\title{
Assessing patients' preferences for characteristics associated with homeopathic and conventional treatment of asthma: a conjoint analysis study
}

\author{
J Ratcliffe, R Van Haselen, M Buxton, K Hardy, J Colehan, M Partridge
}

Thorax 2002;57:503-508

See end of article for authors' affiliations

.....................

Correspondence to: Dr J Ratcliffe, RTI Health Solutions, Research

Triangle Institute, Williams

House, Manchester Science

Park, Manchester

M15 6SE, UK :

jratcliffe@rti.org

Revised version received

29 November 2001

Accepted for publication

12 December 2001
Background: A study was undertaken to investigate the preferences of patients with asthma for attributes or characteristics associated with treatment for their asthma and to investigate the extent to which such preferences may differ between patient subgroups.

Methods: The economic technique of conjoint analysis (CA) was used to investigate patients' strength of preference for several key attributes associated with services for the treatment of asthma. A CA questionnaire was administered to two groups of asthma outpatients aged 18 years or older, 150 receiving conventional treatment at Whipps Cross Hospital (WC) and 150 receiving homeopathic treatment at the Royal London Homoeopathic Hospital (RL).

Results: An overall response rate of $47 \%(n=142)$ was achieved. Statistically significant attributes in influencing preferences for both the WC and RL respondents were (1) the extent to which the doctor gave sufficient time to listen to what the patient has to say, (2) the extent to which the treatment seemed to relieve symptoms, and (3) the travel costs of attending for an asthma consultation. The extent to which the doctor treated the patient as a whole person was also a statistically significant attribute for the RL respondents.

Conclusions: This study has shown that aspects associated with the process of delivery of asthma services are important to patients in addition to treatment outcomes. The homeopathic respondents expressed stronger preferences for the doctor to treat them as a whole person than the patients receiving conventional treatment. Overall, the preferences for the attributes included in the study were similar for both groups.
A sthma is a common condition, the prevalence of which is increasing for reasons that are not entirely clear. It can be controlled, but not cured, with continuing conventional medication. Approximately $50 \%$ of asthma patients in the UK have used some form of complementary therapy for their asthma at some stage, and most of these patients have indicated that they derived at least some benefit. ${ }^{1}$ Most trial evidence suggests that homeopathy is effective in treating the symptoms of asthma. ${ }^{2-9}$ The majority of these trials assessed lung function ( $\mathrm{FEV}_{1}, \mathrm{FVC}$, and PEFR) and some also looked at corticosteroid use. The quality of the trials was variable and there was great heterogeneity in the nature of the homeopathic intervention applied (mostly fixed combinations, some individualised homeopathy with single remedies). More and larger ${ }^{10}$ trials are therefore urgently needed to assess properly the role of homeopathy in the management of asthma. ${ }^{11}$

Within health care there is substantial evidence to suggest that, in addition to the treatment outcome (that is, the effectiveness), other aspects of the process of receiving treatment are also important for individuals. ${ }^{12-14} \mathrm{~A}$ recent study by Osman et $a l^{15}$ used conjoint analysis to assess the relative importance of common symptoms to patients with asthma. However, little is known about how patients value the process of the delivery of asthma services. It is likely that patients have clearly defined preferences about characteristics of the care provided and these preferences may differ between different subgroups of patients. In planning the provision of homeopathic as well as conventional services for asthma patients, information on the benefits associated with characteristics of the process of service delivery need to complement information on the efficacy and costs of the treatment provided.

The main objective of this study was to estimate the relative importance attached to characteristics of the process and out- comes of service delivery for the treatment of asthma for patients presently receiving conventional and/or complementary treatment. The economic technique of conjoint analysis $(\mathrm{CA})^{16}{ }^{17}$ was used to assess patient preferences. CA is one of a number of "stated preference" techniques used to determine individual preferences in hypothetical controlled experimental conditions. Such techniques have been used extensively by market researchers ${ }^{18}$ to determine consumer preferences for a range of goods and services in the transport sector, ${ }^{19}$ to determine passengers' valuation of time and the valuation of other journey related attributes, ${ }^{20} 21$ and has been recommended to the UK Treasury as a tool for determining consumers' preferences for improvements in the quality of service provision in the public utilities. ${ }^{22}$

Within health care, CA can be used to establish the relative importance of different attributes (that is, characteristics or features) in the provision of services, patients' strength of preference for those characteristics, and the overall utility or satisfaction gained from a defined health care service. Where cost is included as an attribute, it is also possible to estimate willingness to pay for improvements in individual attributes. ${ }^{16}$ In recent years CA has begun to be applied within the health care sector. ${ }^{12-14} 23-26$

\section{METHODS}

\section{Establishing the attributes and their levels}

To identify the key attributes or features of homeopathic and conventional treatment for asthma, an initial literature review was undertaken coupled with consultation with clinicians involved in the administration of conventional and homeopathic treatment for asthma. A series of semi-structured one to one interviews was also conducted with four patients 


\section{Attributes used in the study}

- Extent to which the doctor gives sufficient time to listen to what the patient has to say and discusses the treatment options.

- Extent to which the treatment seems to relieve the patient's symptoms.

- Chance of experiencing side effects from the treatment-for example, weight gain, throat irritation, or changes in the character of the voice.

- Extent to which the patient sees the same doctor for every visit concerning the treatment of their asthma.

- Extent to which the doctor treats the patient as a whole person rather than just treating their symptoms.

- Travel cost associated with attendance for an asthma consultation.

\begin{tabular}{|c|c|c|}
\hline Attribute & Label & Codings \\
\hline $\begin{array}{l}\text { Extent to which the doctor } \\
\text { gives sufficient time to } \\
\text { listen .... }\end{array}$ & TIMEDIFF & $\begin{array}{l}\text { - Always }=2 \\
\text { - Sometimes=1 } \\
\text { - Rarely=0 }\end{array}$ \\
\hline $\begin{array}{l}\text { Extent to which treatment } \\
\text { seems to relieve symptoms }\end{array}$ & RELIEVEDIFF & $\begin{array}{l}\text { - } \text { Completely=3 } \\
\text { - } \text { Mostly=2 } \\
\text { - Partially=1 } \\
\text { - Rarely=0 }\end{array}$ \\
\hline $\begin{array}{l}\text { Chance of experiencing } \\
\text { side effects from treatment }\end{array}$ & EFFECTSDIFF & $\begin{array}{l}\text { - } 1 \text { in } 5=20 \% \\
\text { - } 1 \text { in } 10=10 \% \\
\text { - } 1 \text { in } 25=4 \%\end{array}$ \\
\hline $\begin{array}{l}\text { Extent to which the patient } \\
\text { sees the same doctor for } \\
\text { every visit .... }\end{array}$ & TREATDIFF & $\begin{array}{l}\text { - Always }=2 \\
\text { - Sometimes=1 } \\
\text { - Never=0 }\end{array}$ \\
\hline $\begin{array}{l}\text { Extent to which the doctor } \\
\text { treats the patient as a } \\
\text { whole person .... }\end{array}$ & WHOLEDIFF & $\begin{array}{l}\text { - } \text { Does }=1 \\
\text { - } \text { Does not=0 }\end{array}$ \\
\hline $\begin{array}{l}\text { Travel costs of attending } \\
\text { asthma consultation }\end{array}$ & TRAVELDIFF & $\begin{array}{l}\text { - } £ 0=0 \\
\text { - } £ 10=10 \\
\text { - } £ 25=25 \\
\text { - } £ 40=40\end{array}$ \\
\hline
\end{tabular}

attending the Royal London Homoeopathic Hospital for asthma treatment. The interviewees were informed that the purpose of the meeting was to find out the key characteristics of homeopathic treatment for asthma that distinguished it from conventional treatment. Interviews were recorded and transcribed. A grounded theory approach was used, enabling emerging themes to be developed.

The characteristics that emerged from this process were then formulated into attributes (box 1). The levels for each attribute were carefully chosen by the research team to reflect plausible ranges reflecting realistic levels for patients receiving treatment for their asthma.

The technique requires that the chosen attribute levels should be realistic and sensible to respondents and capable of being traded off against each other ${ }^{22}$; trade offs arise where respondents are prepared to substitute a deterioration in one attribute for an improvement in another attribute within a discrete choice experimental design. The levels chosen for each of the attributes in the study and their codings are detailed in table 1 .

\section{Producing and pairing scenarios}

Not all possible scenarios (combinations of attribute levels) can be included in the CA exercise for valuation by respondents, so the computer software package SPEED version
2.1 was used to reduce the number of scenarios down to a manageable level for the purposes of a self-completion questionnaire. ${ }^{27}$ The technique used by SPEED produces an orthogonal main effects design which ensures that there is no multicollinearity between the independent variables (these reflecting the attributes of asthma services). The SPEED software produced 16 scenarios for comparison. For ease of completion and understanding, a discrete choice experimental design was used in which respondents were offered a series of pairwise comparisons between scenarios and asked to indicate their preferred option. A random number generator was used to place the 16 scenarios into eight pairwise choices. The choices were then examined, through correlations of the coefficients of the attribute differences, to check that the principle of orthogonality had been preserved. The frequencies of the attribute levels confirmed that these were balanced. For each pair of scenarios respondents were asked to indicate what choice they would make when receiving treatment for their asthma if asked to choose between two centres as described in the pair of scenarios (see Appendix 1 for an example of a choice set included within the questionnaire).

\section{Selecting the sample and administering the questionnaire}

Two hospitals in inner London were selected to participate in the study, the Royal London Homoeopathic Hospital (RL) and Whipps Cross Hospital (WC). Ethics committee approval was obtained at each hospital. A small pilot survey $(n=30)$ was conducted in advance of the main study to check that patients understood the questions and were completing the choice tasks as instructed. The results from the pilot study indicated that this was the case, so no changes were made to the design of the questionnaire as a consequence of the pilot study. The main questionnaire was administered by post to 300 randomly chosen asthma outpatients aged 18 years or older, 150 of whom were receiving conventional treatment for asthma at WC and 150 who were receiving homeopathic treatment for asthma at the RL. The sample size was chosen based on the expected response rate and the desire to partition the data set to analyse preferences across patient subgroups.

The questionnaire comprised three main sections. In the first section (section A) respondents were asked to indicate the degree of importance of nine characteristics of services for asthma treatment. The characteristics were chosen to reflect the attributes included in the CA exercise plus several other factors which were considered to be of importance by members of the research team. In section B the respondents were presented with eight pairwise choices comprising the CA exercise, and in section $\mathrm{C}$ sociodemographic details were requested. In addition, respondents were asked to indicate how easy/difficult they found the research instrument was to complete and the amount of time they had spent completing it.

The questionnaire was sent to the study participants with a covering letter from a clinician who had been involved in their care at the relevant hospital and a freepost return envelope. One reminder was sent to non-respondents after approximately 4 weeks.

\section{Analysis of data}

The data were analysed using the random effects probit model because of the repeated measurements of the data (whereby multiple responses are obtained from the same individual). ${ }^{23}$ The function to be estimated was of the form:

$$
\mathrm{V}={ }_{1} \text { TIME }+{ }_{2} \text { RELIEVE }+{ }_{3} \text { EFFECT }+{ }_{4} \text { TREAT }+{ }_{5} \text { WHOLE }
$$$$
+ \text { TRAVEL }+\mathrm{e}+\mathrm{u}
$$

where $\mathrm{V}$ is the utility or satisfaction associated with alternative modes of service delivery, 1-6 are the parameters of the model to be estimated as described in table 1 , and e and $u$ are the unobservable error terms where e is due to differences 


\begin{tabular}{|c|c|c|c|c|}
\hline Characteristics & WC respondents, $n$ (\%) & RL respondents, $\mathrm{n}(\%)$ & WC non-respondents, $\mathrm{n}(\%)$ & RL non-respondents, $n(\%)$ \\
\hline \multicolumn{5}{|l|}{ Sex } \\
\hline Male & $17(24 \%)$ & $13(19 \%)$ & $45(58 \%)$ & $26(33 \%)$ \\
\hline Female & $55(76 \%)$ & $57(81 \%)$ & $33(42 \%)$ & $54(66 \%)$ \\
\hline \multicolumn{5}{|l|}{ Age } \\
\hline $18-40$ & $28(39 \%)$ & $20(29 \%)$ & & \\
\hline $41-60$ & $28(39 \%)$ & $29(41 \%)$ & & \\
\hline $61-75$ & $8(11 \%)$ & $13(19 \%)$ & & \\
\hline $75+$ & $1(1 \%)$ & $5(7 \%)$ & & \\
\hline Missing & $7(10 \%)$ & $3(4 \%)$ & & \\
\hline \multicolumn{5}{|c|}{ Length of time with asthma: } \\
\hline$<12$ months & $1(1 \%)$ & $2(3 \%)$ & & \\
\hline $1-4$ years & $12(17 \%)$ & $3(4 \%)$ & & \\
\hline $5-10$ years & $11(15 \%)$ & $18(26 \%)$ & & \\
\hline$>10$ years & $48(67 \%)$ & $47(67 \%)$ & & \\
\hline \multicolumn{5}{|c|}{ Receiving complementary treatments: } \\
\hline Yes & $6(8 \%)$ & $58(83 \%)$ & & \\
\hline No & $66(92 \%)$ & $11(16 \%)$ & & \\
\hline Missing & - & $1(1 \%)$ & & \\
\hline \multicolumn{5}{|c|}{ Ever received complementary treatments: } \\
\hline Yes & $9(13 \%)$ & $24(34 \%)$ & & \\
\hline No & $57(79 \%)$ & $5(7 \%)$ & & \\
\hline Missing & $6(8 \%)$ & $41(59 \%)$ & & \\
\hline \multicolumn{5}{|c|}{ Preference for being in control of treatment decisions } \\
\hline Yes & $46(64 \%)$ & $57(81 \%)$ & & \\
\hline No & 24 (33\%) & $11(16 \%)$ & & \\
\hline Missing & $2(3 \%)$ & $2(3 \%)$ & & \\
\hline \multicolumn{5}{|c|}{ Daily newspaper most often read: } \\
\hline Daily Mirror/Sun & $13(18 \%)$ & $3(4 \%)$ & & \\
\hline Daily Mail & $21(29 \%)$ & $11(16 \%)$ & & \\
\hline Daily Telegraph & $5(7 \%)$ & $5(7 \%)$ & & \\
\hline Independent & $1(1 \%)$ & $8(11 \%)$ & & \\
\hline Guardian & $9(13 \%)$ & $20(29 \%)$ & & \\
\hline Times & $6(8 \%)$ & $9(13 \%)$ & & \\
\hline Other & $17(24 \%)$ & $14(20 \%)$ & & \\
\hline \multicolumn{5}{|l|}{ Townsend scores } \\
\hline-5 to -2.5 & $13(18 \%)$ & $18(26 \%)$ & $18(23 \%)$ & 11 (14\%) \\
\hline-2.49 to 0 & 14 (19\%) & $12(17 \%)$ & $13(17 \%)$ & $16(20 \%)$ \\
\hline 0.1 to 2.49 & 14 (19\%) & $20(29 \%)$ & $27(35 \%)$ & $19(24 \%)$ \\
\hline 2.5 to 5 & 24 (33\%) & 13 (19\%) & 15 (19\%) & $21(26 \%)$ \\
\hline+5 & $7(10 \%)$ & $7(10 \%)$ & $5(6 \%)$ & $13(16 \%)$ \\
\hline
\end{tabular}

Percentages are rounded and do not always add up to $100 \%$

WC=Whipps Cross Hospital; RL=Royal London Homoeopathic Hospital.

in observations and $\mathrm{u}$ is due to differences among respondents. The estimated coefficients indicate the relevant importance of the different attributes on individual preferences. In general, the higher the size of the coefficient, the greater the importance of the attribute in determining overall utility or satisfaction (although, where different units of measurement of the attributes have been used, care must be taken in interpreting these results). A positive sign on a coefficient indicates that, as the level of the attribute increases, so does the utility derived, and the converse applies for a negative sign. The statistically significant levels of each coefficient were indicated. It is possible to estimate willingness to pay for improvements in individual attributes by dividing the coefficient of interest by the coefficient attached to travel cost. For example, it is possible to estimate patients' willingness to pay for an improvement in symptom relief by dividing the coefficient on symptom relief by the coefficient on travel cost $\left({ }_{2}\right.$ RELIEVE/ ${ }_{6}$ TRAVEL).

For each respondent, tests were carried out to see if any of the attributes were dominant. ${ }^{28} 29$ A dominant attribute implies that the scenario with the higher level of this attribute is always chosen, irrespective of the levels of the remaining attributes.

For policy purposes it is often important to ascertain the extent to which preferences vary across subgroups of respondents. Such analysis is possible for subgroups with more than 30 observations. ${ }^{30}$ The data were segmented firstly by hospital and secondly by education level to test for significant differences in preferences across these subgroups. A pri- ori, it was expected that there would be significant differences in preferences between the RL and WC respondents. In particular, it was expected that the RL respondents would have a strong preference for continuity of carer, for the doctor to treat them as a whole person, and for the probability of experiencing side effects from treatment to be as low as possible. In contrast, it was expected that the WC respondents would be less concerned about the doctor treating them as a whole person and experiencing side effects from treatment but would have a strong preference for symptom relief.

Dummy variable interaction terms were created between all of the attributes and a dummy variable for hospital where this was defined in terms of the two groups: RL (coded 1 or 0 ) and WC (coded 1 or 0 ). Similarly, dummy variable interaction terms were created between all of the attributes and a dummy variable for education where this was defined in terms of four levels: "no" qualifications (base case), "O" level qualifications (coded 1 or 0 ), " $\mathrm{A}$ " level qualifications (coded 1 or 0 ), and degree ("D" level qualifications (coded 1 or 0 ). The Wald statistic was calculated to test for statistically significant differences on the coefficients according to hospital group and education level.

\section{RESULTS}

Characteristics of respondents and response patterns

A total of 142 questionnaires were returned (overall response rate $47 \%$ ) of which 72 were from the conventional treatment 
Table 3 Importance of characteristics of asthma service

\begin{tabular}{|c|c|c|c|c|c|c|c|c|}
\hline \multirow[t]{2}{*}{ Feature } & \multicolumn{2}{|c|}{ Very important } & \multicolumn{2}{|c|}{ Quite important } & \multicolumn{2}{|c|}{ Not very important } & \multicolumn{2}{|l|}{ Missing } \\
\hline & $W C, \%(n)$ & $\mathrm{RL}, \%$ (n) & WC, \% (n) & $R L, \%(n)$ & WC, \% (n) & $\mathrm{RL}, \%$ (n) & WC, \% (n) & $R L, \%(n)$ \\
\hline $\begin{array}{l}\text { Choose the course of } \\
\text { treatment which is best for } \\
\text { you }\end{array}$ & $53 \%(38)$ & $80 \%(56)$ & $32 \%(23)$ & $16 \%(11)$ & $12 \%(9)$ & $1 \%(1)$ & $3 \%(2)$ & $3 \%(2)$ \\
\hline $\begin{array}{l}\text { Doctor listens and } \\
\text { discusses treatment } \\
\text { options }\end{array}$ & $96 \%(69)$ & $96 \%(67)$ & $4 \%(3)$ & $3 \%(2)$ & & & & $1 \%(1)$ \\
\hline $\begin{array}{l}\text { Side effects of treatment } \\
\text { are minimal }\end{array}$ & $81 \%(58)$ & $93 \%(65)$ & $19 \%(14)$ & $4 \%(3)$ & & & & $3 \%(2)$ \\
\hline $\begin{array}{l}\text { You see the same doctor } \\
\text { at each visit }\end{array}$ & $67 \%(48)$ & $66 \%(46)$ & $32 \%(23)$ & $29 \%(20)$ & $1 \%(1)$ & $4 \%(3)$ & & $1 \%(1)$ \\
\hline $\begin{array}{l}\text { Information about asthma } \\
\text { and the treatment you } \\
\text { receive }\end{array}$ & $81 \%(58)$ & $71 \%(50)$ & $16 \%(12)$ & $23 \%(16)$ & $3 \%(2)$ & $3 \%(2)$ & & $3 \%(2)$ \\
\hline $\begin{array}{l}\text { Doctor treats you as a } \\
\text { whole person }\end{array}$ & $78 \%(56)$ & $93 \%(65)$ & $22 \%(16)$ & $4 \%(3)$ & & & & $3 \%(2)$ \\
\hline $\begin{array}{l}\text { Confidence in the } \\
\text { doctor's skills and ability }\end{array}$ & $92 \%(66)$ & $93 \%(65)$ & $8 \%(6)$ & $4 \%(3)$ & & & & $3 \%(2)$ \\
\hline $\begin{array}{l}\text { The place of consultation } \\
\text { is near to the patient's } \\
\text { home }\end{array}$ & $47 \%(34)$ & $23 \%(16)$ & $31 \%(22)$ & $53 \%(37)$ & $22 \%(16)$ & $21 \%(15)$ & & $3 \%(2)$ \\
\hline $\begin{array}{l}\text { Costs to the patient are } \\
\text { minimal }\end{array}$ & $42 \%(30)$ & $46 \%(32)$ & $26 \%(19)$ & $31 \%(22)$ & $29 \%(21)$ & $19 \%(13)$ & $3 \%(2)$ & $4 \%(3)$ \\
\hline
\end{tabular}

sample and 70 from the homeopathic treatment sample. The descriptive characteristics of responders are summarised in table 2 .

It was possible to obtain some information by which the characteristics of responders and non-responders could be compared. Postal code information was used to calculate Townsend scores, ${ }^{31}$ an indicator of relative deprivation. The Townsend score has a national (England and Wales) mean value of zero; scores higher than zero indicate relative deprivation and those less than zero indicate relative affluence. It was found that there were no statistically significant differences between the responders and non-responders at each hospital by Townsend scores $(\mathrm{p}=0.161 \mathrm{WC}, \mathrm{p}=0.296$ RL, Wilcoxon test). However, men were overrepresented within the non-respondents and this difference was found to be statistically significant at WC $(p<0.001 \mathrm{WC}, \mathrm{p}=0.053 \mathrm{RL}$, Wilcoxon test).

There were differences between respondents in age, with respondents from RL being older on average than those from WC. There were no significant differences between respondents in sex or the length of time they had suffered from asthma. As expected, there were differences in the extent to which complementary therapies were being used and had been used in the past. There were also differences in their desire to be in control of treatment decisions and in the daily newspaper most often read.

\section{Importance of service characteristics}

The results from section A of the questionnaire (where respondents were asked to indicate the degree of importance of nine characteristics of services for asthma treatment) are presented in table 3.

Compared with those receiving conventional treatment for asthma, patients receiving homeopathic treatment thought it "very important" that they should be able to choose a course of treatment which is best for them, that the side effects of treatment are minimal, and that the doctor treated them as a whole person. Conversely, patients receiving conventional treatment for asthma were relatively more concerned that the place of consultation should be near to their home and to receive information about asthma and the treatment they received.

\begin{tabular}{lll} 
Table 4 & Random effects probit model results \\
\hline Attributes & Coefficient & $95 \% \mathrm{Cl}$ \\
\hline TIME* $^{*}$ & 0.1370 & 0.0509 to 0.2230 \\
RELIEVE* $_{\text {EFECT }}$ & 0.3973 & 0.2758 to 0.5188 \\
TREAT* & -0.0015 & -0.0155 to 0.0126 \\
WHOLE* & 0.1471 & 0.0371 to 0.2571 \\
TRAVEL* & 0.2289 & 0.1010 to 0.3569 \\
\hline No of observations $=959 ;$ no of groups $=129 ;$ observations per \\
group (min/average/max) $=8 / 8 / 8 ; \chi^{2}=117.77$ (p<0.001); \\
*significant at $5 \%$ level.
\end{tabular}

\section{Conjoint analysis model estimation}

The results of the random effects probit regression model for the total sample of respondents are presented in model 1 (table 4). All coefficients had the expected sign. The statistically significant attributes in influencing preferences for respondents as a whole were:

- the extent to which the doctor gives sufficient time to listen with respondents preferring more time to less;

- the extent to which the treatment seems to relieve symptoms with respondents preferring treatments with a greater potential to relieve symptoms;

- the extent to which the patients see the same doctor on every visit to the hospital with respondents preferring to see the same doctor rather than several doctors during a course of treatment;

- the extent to which the doctor treats the patient as a whole person with respondents preferring the doctor to treat them as a whole person;

- the travel costs of attending for an asthma consultation with respondents preferring lower costs to higher costs.

As in other CA studies in health care, ${ }^{24} 26$ a relatively high proportion of respondents exhibited dominant preferences for one of the attributes included in the questionnaire (table 5). In this exercise the extent of symptom relief was, not surprisingly, the most common dominant attribute.

The statistically significant attributes in influencing the preferences of the non-dominant respondents were similar to 
Table 5 Respondents exhibiting dominant preferences

\begin{tabular}{lcc}
\hline Attributes & WC, $n(\%)$ & RL, n (\%) \\
\hline $\begin{array}{l}\text { Extent to which the doctor gives sufficient } \\
\text { time to listen ... }\end{array}$ & $3(4)$ & $9(13)$ \\
$\begin{array}{l}\text { Extent to which the treatment seems to } \\
\text { relieve your symptoms }\end{array}$ & $28(40)$ & $27(39)$ \\
$\begin{array}{l}\text { Chance of experiencing side effects from the } \\
\text { treatment ... }\end{array}$ & $3(4)$ & $10(14)$ \\
$\begin{array}{l}\text { Extent to which you see the same doctor } \\
\text { every time you visit ... }\end{array}$ & $2(3)$ & 2 (3) \\
$\begin{array}{l}\text { Extent to which the doctor treats you as a } \\
\text { whole person ... }\end{array}$ & $11(16)$ & $7(10)$ \\
$\begin{array}{l}\text { Travel costs of attending for your asthma } \\
\text { consultation }\end{array}$ & $4(6)$ & $1(1)$
\end{tabular}

those of all respondents, with the same direction of preference. The only exception was the extent to which the doctor gives sufficient time to listen which did not achieve statistical significance for the non-dominant respondents.

Segmentation of the data according to hospital indicated that statistically significant attributes in the preferences of RL respondents were symptom relief, the extent to which the doctor treated them as a whole person, and travel costs; they preferred greater symptom relief, for the doctor to treat them as a whole person, and lower travel costs. Symptom relief and travel costs were also statistically significant in influencing the preferences of the WC respondents with the same direction of preference as for the RL respondents. In comparison with the RL respondents, however, the WC respondents were less concerned about the extent to which the doctor treated them as a whole person, but more concerned about the extent to which the doctor gives sufficient time to listen to the patient.

Segmentation of the data according to education indicated that the extent to which the doctor treated them as a whole person rather than just treating the symptoms became more important as the education level increased, with this attribute being highly significant in influencing preferences for those with degree level education.

\section{DISCUSSION}

The findings from this study are consistent with those of other studies which have used CA to establish patient preferences in other treatment areas ${ }^{12}{ }^{14} 24$ in establishing that the benefits of health care to patients include the process of service delivery in addition to treatment outcomes. However, such findings have not traditionally been incorporated into the common measures of the benefit of health care interventions used within health economics.

The results from section A of the questionnaire indicate the importance placed by respondents on good communication between those with a long term condition and their health care provider. Almost all of the respondents thought it very important that the doctor should listen and discuss the treatment options with the patient, and most respondents from both hospital samples felt it very important that the doctor should treat the patient as a whole person. These patient preferences agree with the results of other studies which show a positive correlation between good doctor/patient communication and compliance. ${ }^{32}{ }^{33}$ Most respondents from both samples also expressed a preference for being in control of treatment decisions, and such self-management has increasingly been shown to be associated with successful asthma outcomes. ${ }^{34}$ Those organising health care services for patients with asthma also need to note the clear message from respondents of the importance of seeing the same doctor on every visit to the asthma clinic.
In general, the results from the CA exercise for all respondents (section $\mathrm{B}$ ) reinforce the findings from section $\mathrm{A}$ of the questionnaire. It was found that all of the attributes were statistically significant in influencing preferences, with the exception of the chance of experiencing side effects from the treatment given. The relative unimportance of the side effects attribute within the CA exercise is somewhat surprising, given its prominence in the responses to section A where $81 \%$ of WC and $93 \%$ of RL respondents indicated that they considered it very important that the side effects of treatment are kept to a minimum. These apparently contradictory results may be explained by problems of patients' perception of risk or problems with their comparison of probabilistic risk statements. ${ }^{35}$ It is possible that the inclusion of a wider range of levels of risk for the side effect attribute would have resulted in them placing greater importance on this attribute. Similarly, it is also possible that the observed choice pattern of the large number of dominant respondents is a consequence of the choices presented. The inclusion of a different set of levels for some or all of the attributes presented may have encouraged these respondents to trade off the attributes. However, it is also important to ensure that the levels chosen for the attributes appear plausible to respondents. The attribute levels included within this exercise were carefully chosen to reflect realistic levels for patients receiving treatment for their asthma.

A comparison of patients receiving conventional and homeopathic treatment for asthma revealed some differences in preferences within the CA exercise, particularly the finding that patients receiving homeopathic treatment had a stronger preference for the doctor to treat them as a whole person (this finding reinforced the earlier finding from the responses to section A of the questionnaire where, relative to WC respondents, a greater proportion of RL respondents thought it very important that the doctor treated them as a whole person). Overall, the differences in preferences between the two groups were not as pronounced as was expected a priori, and the results suggest that both groups of patients attach value to common aspects of service delivery. The UK Government's plan for the National Health Service is to offer people fast and convenient care delivered to a consistently high standard and to make services available when people require them, tailored to their individual needs. ${ }^{36}$ The results of this study suggest that the needs of patients with asthma receiving either homeopathic or conventional treatment are very similar and include enhanced communication between the doctor and patient, treatment which is effective in relieving the symptoms of asthma, continuous care by the same health care professional(s), and close geographical proximity to asthma services

The response rate to this questionnaire may represent a limitation since it is not possible to rule out responder bias in the results presented. The response rate achieved is in keeping with several recent studies that have used the CA technique to elicit patient or public preferences for health care treatments. ${ }^{13}{ }^{14} 26$ However, if the results of such studies are to be used as a firm basis for policy making, it is important that higher response rates are achieved in the future. Alternative elicitation techniques such as computer assisted interviewing or web based approaches may aid this process.

This paper has described the application of the CA technique to the measurement of patients' preferences for characteristics of asthma. This CA study is the first, to our knowledge, relating to homeopathic treatment, and has shown that characteristics associated with the process of care provided are important to asthmatic patients receiving both conventional and homeopathic treatment. CA is a potentially useful tool for assessing patient preferences for alternative modes of delivery of asthma services. 


\section{APPENDIX 1: EXAMPLE OF CHOICE SET INCLUDED WITHIN THE QUESTIONNAIRE}

\begin{tabular}{|c|c|c|}
\hline Pair 1 & Place A & Place B \\
\hline $\begin{array}{l}\text { Extent to which the doctor gives sufficient time to listen to what you have } \\
\text { to say and discusses your treatment options with you }\end{array}$ & Rarely & Sometimes \\
\hline Extent to which the treatment seems to relieve your symptoms & Mostly & Mostly \\
\hline $\begin{array}{l}\text { Chance of receiving side effects from the treatment you are given for your } \\
\text { asthma }\end{array}$ & 1 in 25 chance & 1 in 5 chance \\
\hline $\begin{array}{l}\text { Extent to which you see the same doctor every time you visit concerning } \\
\text { the treatment of your asthma }\end{array}$ & You always see the same doctor & You always see the same doctor \\
\hline $\begin{array}{l}\text { Extent to which the doctor sees you as a whole person rather than just } \\
\text { treating your symptoms }\end{array}$ & $\begin{array}{l}\text { The doctor does not treat me as a } \\
\text { whole person and does just treat my } \\
\text { symptoms }\end{array}$ & $\begin{array}{l}\text { The doctor does treat me as a whole } \\
\text { person and does not just treat my } \\
\text { symptoms }\end{array}$ \\
\hline Travel costs to you of attending for your asthma consultation & $£ 0$ per visit & $£ 0$ per visit \\
\hline Which place would you choose? (Please tick one only) & A: & B: \\
\hline
\end{tabular}

\section{ACKNOWLEDGEMENTS}

This work was undertaken while Julie Ratcliffe was based at the Health Economics Research Group at Brunel University. The authors are grateful to all of the patients who participated in this study. The study was jointly funded by the Department of Health, Policy Research Programme, Programme Grant to the Health Economics Research Group at Brunel University and the Royal London Homoeopathic Hospital from existing resources.

\section{Authors' affiliations}

J Ratcliffe, M Buxton, J Colehan, Health Economics Research Group, Brunel University, Uxbridge, Middlesex, UK

R Van Haselen, K Hardy, Academic Research Unit, Royal London Homoeopathic Hospital, London, UK

M Partridge, Department of Respiratory Medicine, Whipps Cross

Hospital, London, UK

\section{REFERENCES}

Partridge MR. Complementary medicine for asthma. Asthma J 1998;3:6.

2 Reilly D, Taylor M, Beattie NGM, et al. Is evidence for homeopathy reproducible. Lancet 1994;344:1601-6.

3 Freitas LAS, Goldenstein E, Sanna OM. The indirect doctor-patient relationship and the homeopathic treatment of asthma in children. Revista Homeopatia 1995:60:26-31.

4 Matusiewicz R. Wirksamkeit von Engystol N bei Bronchialasthma unte kortikoidabhängiger Therapie. Biologische Medizin 1995;24:242-6.

5 Matusiewicz $\mathbf{R}$. The homeopathic treatment of corticosteroid-dependent asthma: a double blind, placebo-controlled study. Biomed Ther 1997; 15:117-22.

6 Matusiewicz R, Wasniewski J, Sterna-Bazanskza A, et al. Behandlung of chronic asthma bronchiale mit einem homoopathischen Komplexmittel. Erfahrungsheilkunde 1999;48:367-74.

7 Jansen GR, Koster TG, Haidvogl M, et al. The homeopathic treatment of asthma: a randomized clinical trial. Proc 52nd LMHI Congress, Seattle, USA 1997: 74-80.

8 Lara-Marquez ML, Pocino M, Rodriguez F, et al. Homeopathic treatment for atopic asthma lung function and immunological outcomes in a randomized clinical trial in Venezuela. Proc 52nd LMHI Congress, Seattle, USA 1997: 73

9 Riveron-Garotte M, Arguelles-Fernandez R, Moron-Rodriguez F, et al. Ensayo clinico controlado aleatorizado del tratamiento homeopatico del asma bronquial. Bol Mex Hom 1998;31:54-61

10 Vickers A. Commentary: larger trials are needed. BM 2000;321:476.

11 Linde K, Jobst KA. Homeopathy for chronic asthma (Cochrane Review) In: The Cochrane Library. Issue 2. Oxford: Update Software, 2001.

12 Ratcliffe J, Buxton M. Patients preferences regarding the process and outcomes of life saving technology. An application of conjoint analysis to liver transplantation. Int J Technol Assess Health Care 1999;15:340-52.

13 Ryan M, Hughes J. Using conjoint analysis to assess women's preferences for miscarriage management. Health Econ 1997;6:261-74.
14 Ryan M. Using conjoint analysis to take account of patient's preferences and go beyond health outcomes. An application to in-vitro fertilisation. Soc Sci Med 1999:48:535-46.

15 Osman LM, McKenzie L, Cairns J, et al. Patient weighting of importance of asthma services. Thorax 2001:56:138-42.

16 Ryan M. The application of conjoint analysis in health care. London: OHE Publications, 1996

17 Ryan M, Farrar S. Using conjoint analysis to elicit preferences for health care. BN 2000;320:1530-3

18 Cattin P, Wittink D. Commercial use of conjoint analysis: a survey. J Marketing 1982;46:44-53.

19 Carroll J, Douglas Green PE. Psychometric methods in marketing research: Part 1 conjoint analysis. J Marketing Res 1995;32:385.

20 Bates J. Sensitivity to level of service: evidence from stated preference work. Behav Res Transport Policy 1986;13: 289-305.

21 Wardman M. Route choice and the value of motorists travel time: empirical findings. Institute for Transport Studies Working Paper 224, University of Leeds, 1986

22 Cave $M$, Burningham D, Buxton $M$, et al. The valuation of changes in quality in public services. London: HMSO, 1994.

23 Propper C. The disutility of time spent on the UK's NHS waiting lists. J Human Resources 1995;30:677-700.

24 Bryan S, Buxton $M$, Sheldon $R$, et al. The use of magnetic resonance imaging for the investigation of knee injuries: an investigation of preferences. Health Econ 1998; 7:595-604.

25 Van der Pol M, Cairns J. Establishing patient's preferences for blood transfusion support: an application of conjoint analysis. J Health Serv Res Policy 1997;3:70-6.

26 Ryan M, Mclntosh E, Dean T. Trade offs between location and waiting time in the provision of health care: the case of elective surgery on the Isle of Wight. J Public Health Med 2000;22:202-10.

27 Bradley M. User's manual for the SPEED Version 2.1. Stated preference experiment editor and designer. Hague Consulting Group, 1991.

28 Drakopoulos SA. Hierarchical choice in economics. J Econ Surv 1994;8:133-53.

29 Scott A. Giving things up to have more of others. The implications of limited substitutability for eliciting preferences in health and health care. HERU Discussion paper No 01/98, University of Aberdeen, 1998.

30 Pearmain D, Swanson J, Kroes E, et al. Stated preference techniques: a guide to practice. The Hague: Steer Davis Gleave and Hague Consulting Group, 1991

31 Townsend $\mathbf{P}$, Phillimore $\mathrm{P}$, Beattie A. Health and deprivation: inequality and the north. London: Croom Helm, 1988.

32 Korsch BM, Negrette F. Doctor patient communication. Sci Am 1972;227:66-72.

33 Apter AT, Reising ST, Affleck G, et al. Adherence with strict daily dosing of inhaled steroids: socioeconomic and health belief difference. Am J Respir Crit Care Med 1998;157:1810-7.

34 Gibson PG, Coughlan J, Abrahamson M. Effects of self management education and regular practitioner review in adults with asthma (Cochrane Review). In: Cochrane Library. Issue 1. Oxford: Update Software, 1999

35 Schoemaker PJH. The expected utility model: its variants, purposes, evidence and limitations. J Econ Lit 1982;20:529-63.

36 Department of Health. The NHS plan. A plan for investment. A plan for reform. London: Department of Health, 2000. 